\title{
MÉTODO DE PROBLEMAS NO ENSINO DE FÍSCA
}

\author{
ismael Ribeiro de Assis, Ana Paula Stoppa Rabelo, Mauro Antonio Andreata.
}

\author{
1. Departamento de Física, Universidade Federal de Goiás - Campus Catalão \\ Caixa Postal 536, 75704-020 Catalão, GO
}

Emails: ismaelribeiro9@hotmail.com, paula-catalao@hotmail.com, mauroandreata@yahoo.com.br ${ }^{2}$

\begin{abstract}
In this paper, we present our work at the partner school, Colégio Estadual Dona Iayá, in Catalão/GO, through the, Programa Institucional de Bolsa de Iniciação à Docência (PIBID). Observations showed us that in the high school still occurring the practices of traditional teaching, where the teacher is at "the center", and the student just take notes, turning the class inert and separating the real world (life) from school. In the intent of changing this reality and instigate the students to learn more about Physics, we used the problems method created by John Dewey (1859-1952). This method induces the habit of the "reflective thinking", which according to Dewey, is the best way of think. We chose this method because it allows exercise the reflective thinking, minimizing the separation between life and school.
\end{abstract}

Keywords_ Problems Method, reflective thinking, teaching Physics;

Resumo- Neste trabalho, apresentamos o nossa atuação na escola parceira, Colégio Estadual Dona Iayá, em Catalão / GO, através do Programa Institucional de Bolsa de Iniciação à Docência (PIBID). Observações nos mostraram que no Ensino Médio ainda ocorrem às práticas de ensino tradicional, em que o professor está em "centro", e que o aluno apenas tomar notas, transformando a classe inerte e separar o mundo real (vida) da escola. $\mathrm{Na}$ intenção de mudar essa realidade e instigar os alunos a aprender mais sobre a Física, foi utilizado o método de problemas criados por John Dewey (1859-1952). Este método induz o hábito do "pensamento reflexivo", que de acordo com Dewey, é a melhor maneira de pensar. Escolhemos este método, pois permite o exercício do pensamento , minimizando a separação entre a vida e a escola.

Palavras-chave— Método de problemas, pensamento reflexivo, ensino de Física;

\section{INTRODUÇÃO}

Neste trabalho relatamos a nossa atuação no Colégio Estadual Dona Iayá em Catalão, Goiás, através do Programa Institucional de Bolsa de Iniciação a Docência (PIBID) da Física/UFG/Catalão. Fizemos uma investigação qualitativa do uso método de problemas no ensino de Física. As características da investigação qualitativa são as seguintes (BOGDAN; BIKLEN, 1994, pp. 47-51): 1. Na investigação qualitativa a fonte direta dos dados é o ambiente natural, constituindo o investigador o instrumento principal. 2. A investigação qualitativa é descritiva. 3. Os investigadores qualitativos interessam-se mais pelo processo do que simplesmente pelos resultados ou produtos. 4. Os investigadores qualitativos tendem a analisar os seus dados de forma indutiva. 5. O significado é de importância vital na abordagem qualitativa.

Ressaltemos que a investigação qualitativa é descritiva, ou seja, "os dados recolhidos são em forma de palavras ou imagens e não de números" (BOGDAN; BIKLEN, 1994, p. 48). Além disso,
Os relatórios e artigos qualitativos têm sido classificados por alguns autores como "anedóticos". Isto porque contêm frequentemente citações e tentam descrever, de forma narrativa, em que consiste determinada situação ou visão de mundo. A palavra escrita assume particular importância na abordagem qualitativa, tanto para o registro dos dados como para sua disseminação. (BOGDAN; BIKLEN, 1994, p. 49)

Nossas observações na escola-parceira mostraram ausência de interesse dos alunos, faltalhes motivação para estudar Física. Ainda predominam as práticas educativas da Escola Tradicional, a qual enfatiza a ação do professor e as matérias de ensino. Os métodos são dogmáticos, verbalistas e intelectuais.

Quais são as consequências da verborreia do professor tradicional? "Como consequência natural, o aluno é passivo, grande tomador de notas, exímio memorizador, prefere manejar conceitos abstratos a resolver de forma original e criadora problemas concretos da realidade em que vive" (BORDENAVE; PEREIRA, 2008, p. 10).

Os alunos têm dificuldades em compreender os conceitos físicos e, quando se deparam com questões da matéria, por exemplo, em vestibulares, 
concursos, Enem, etc., seu desempenho é insatisfatório. Nos problemas reais do cotidiano, ou seja, nas questões extraescolares, os educandos nem sequer percebem quais são os conceitos físicos envolvidos.

Visando sanar essas dificuldades, isto é, desejando preparar os alunos para obter melhores resultados em provas e, sobretudo, formar integralmente os educandos (formação intelectual, física e moral), adotamos o método de problemas, desenvolvido pelo filósofo, psicólogo e pedagogo estadunidense John Dewey (1859-1952).

O método de problemas do Dewey “consiste em propor situações problemáticas ao estudante, que terá de pesquisar para resolvê-las. O método de problemas faz ênfase no raciocínio, na reflexão, lidando preponderantemente com ideias ao invés de coisas" (NÉRICI, 1973, p. 292, grifo do autor). Normalmente, ele é desenvolvido em cinco fases ou passos:

1) Primeiro ocorre a tomada de consciência de uma dificuldade, ou de um problema, ou de uma necessidade sentida.

2) Em seguida, vem o exame da situação pela mente até que, por uma análise dos seus vários elementos, ela localiza o cerne da dificuldade e define o fator de maior importância.

3) Seguem-se, então, sugestões quanto a possíveis soluções.

4) As consequências de cada solução sugerida são desenvolvidas e a solução mais provável é submetida à ação, isto é, à experimentação.

5) A observação e experimentação subsequentes levam à aceitação ou recusa da solução. (EBY, 1976, pp. 535-536)

E quais são as vantagens do uso de problemas para a aprendizagem? "A resolução de problemas exercita o pensamento reflexivo, a iniciativa e a capacidade do aluno para organizar e executar por si o trabalho" (AGUAYO, 1970, p. 157).

Recordemos que, segundo Dewey, a melhor maneira de pensar "é chamada pensamento reflexivo: a espécie de pensamento que consiste em examinar mentalmente o assunto e dar-lhe consideração séria e consecutiva" (DEWEY, 1959, p. 13). É um pensar maduro que enriquece as coisas com um sentido: "a função do pensamento reflexivo é a de transformar uma situação na qual se tenham experiências caracterizadas pela obscuridade, pela dúvida, pelo conflito, isto é, de qualquer modo perturbadas, numa situação que seja clara, coerente, ordenada, harmoniosa" (DEWEY apud ABBAGNANO; VISALBERGHI, s/d, p. 766).
Escolhemos o método de problemas porque ele permite exercitar a melhor forma de pensar, ou seja, desenvolve o pensamento reflexivo. Além disso, "a mudança e a contingência são traços genéticos da realidade, a vida apresenta, constantemente, problemas que necessitam de investigação. Em consequência, que método poderia ser mais apropriado ao ensino que o célebre método do problema de Dewey?" (BRUBACHER, 1978, p. 295). Em nosso mundo contemporâneo, caracterizado pela constante mudança e incerteza, os conhecimentos prontos e acabados fornecidos pelo Ensino Tradicional já não são suficientes. O método de problemas é uma das estratégias possíveis para instigar e melhorar a aprendizagem da Física no Ensino Médio.

Para desenvolver o método de problemas, construímos, junto com os alunos do Ensino Médio (EM), com materiais módicos e fáceis de encontrar, um eletroscópio a partir do qual discutimos eletrização, forças elétricas atrativas e repulsivas e a ação de forças elétricas sobre dispositivos mecânicos. A importância e onipresença do eletromagnetismo em nossas vidas determinou nossa escolha do tema.

\section{Propósito}

- Contribuir para a formação intelectual, física e moral dos educandos.

- Aumentar a compreensão dos alunos de modo a diminuir suas dificuldades no estudo da Física do EM.

- Melhorar o ensino-aprendizagem de Física.

- Despertar e manter o interesse dos discentes pela Física.

\section{Métodos}

O eletroscópio de folhas que construímos, em uma das turmas do terceiro ano do EM, é composto por um pote de vidro transparente, fechado com um pedaço de isopor na parte de cima. Pelo isopor passa um fio de cobre adentrando o pote de vidro. No interior do vidro, presas ao fio de cobre, estão duas folhas metálicas de alumínio, e na parte de cima fora do pote, preso ao fio, está uma esfera de alumínio. Ao aproximarmos um corpo eletrizado da esfera de alumínio, ocorre a indução de cargas elétricas no sistema, e as folhas se separam, por possuírem cargas de mesmo sinal. Se o mesmo 
corpo tocar a esfera superior, o eletroscópio também ficará eletricamente carregado.

Para desenvolver o experimento, primeiro consultamos o professor supervisor sobre os conhecimentos prévios dos alunos. Os mesmos já haviam estudado dos conceitos prévios para entender o experimento.

Desenvolvemos o experimento durante duas aulas seguidas (disponibilizadas pelo professor supervisor). No intuito de instiga-los, primeiramente apenas apresentamos o experimento, sem lhes dizer a causa do fenômeno que estavam observando. Logo após a apresentação do experimento começamos uma discussão com os vinte e dois alunos, questionando-os sobre o que acabaram de ver. Dividimos a sala em três grupos e entregamos uma lista com cinco questões a respeito do que foi observado juntamente com um eletroscópio para cada grupo, para que pudessem trabalhar juntos. Os discentes podiam consultar $\mathrm{o}$ livro. Durante a resolução dos exercícios, os alunos discutiram entre si e formularam hipóteses sobre o que havia ocorrido e o motivo pelo qual as lâminas se separaram. Quando necessário, os alunos podiam procurar o professor supervisor ou os bolsistas para receber esclarecimentos em relação aos problemas. Notemos, contudo, que nem o professor e nem os bolsistas forneceram as soluções dos problemas, apenas deram instruções para que o aluno chegasse à solução por conta própria.

Recolhidas as listas resolvidas pelos alunos, nós as corrigimos e avaliamos. Nossa correção permitiu identificar as questões que causaram mais dificuldades para os alunos, a principal dificuldade foi em explicar o conceito Físico por trás da separação das laminas, ou seja, tiveram dificuldade em relacionar o conteúdo que já haviam visto antes em sala de aula com o experimento. Retornamos à escola-parceira para trabalhar este conceito, de forma a tirar toda e qualquer dúvida.

Para avaliar se os discentes haviam compreendido o fenômeno apresentado no experimento, retornamos a escola com uma lista de 10 questões, relacionadas ao experimento e ao conceito Físico. As questões foram trabalhadas em sala de aula. A sala foi divida em duplas, e foi entregue uma lista para cada dupla. Os alunos podiam consultar livros, caderno e pedir orientação para o professor supervisor e para os bolsitas.

\section{Resultados/Discussão}

Os alunos produziram respostas interessantes, mostrando a compreensão dos conceitos e fenômenos físicos envolvidos no eletroscópio de folhas, apesar da dificuldade inicial em compreendê-los.

As listas de questões resolvidas pelos alunos foram recolhidas, corrigidas e avaliadas. A correção permitiu identificar o que de fato os alunos aprenderam. Com a lista de 10 questões trabalhada em sala de aula, notamos que os alunos sanaram as dificuldades em relação ao eletroscópio de folhas, contudo tiveram muita dificuldade em trabalhar com a matemática, por exemplo, trabalhar matematicamente a equação da lei de Coulomb.

$\mathrm{Na}$ primeira lista, havia uma questão pedindo para explicar fisicamente o fenômeno observado (foi a principal dificuldade). A que apenas um dos grupos conseguiu responder de forma correta. $\mathrm{Na}$ segunda lista, fizemos basicamente a mesma pergunta, mas desta vez modificamos o problema, demos um exemplo de um aluno que havia construído um eletroscópio de folhas e ao aproximar um corpo eletrizado, notou um ângulo de abertura entre as folhas do alumínio. Questionamos qual era a causa deste acontecimento? Notamos que quase todas as duplas, responderam de forma correta.

Proporcionamos aos discentes a oportunidade de construir seu próprio conhecimento, o que não é possível em uma aula tradicional e meramente expositiva.

Durante a intervenção, grande interesse dos educandos pelo experimento. Todos os vinte e dois alunos participaram da atividade e tiveram bom desempenho, trabalhando em grupos. Destacamos o esforço deles para resolver todas as questões das listas, as quais nos mostram que os mesmos compreenderam integralmente os conceitos.

\section{Conclusão}

A atividade na escola foi proveitosa para todos os envolvidos. A participação dos alunos foi ostensiva, questionaram, discutiram e se mostraram instigados com o eletroscópio de folhas.

O método de problemas superou nossas expectativas e se mostrou eficaz em despertar o interesse dos discentes.

Acreditamos ter alcançado nossos objetivos, contudo, ressaltamos que o pensamento reflexivo é um hábito, que se não adquire instantenamente, ou seja, precisa ser trabalho continuamente. 
A Física ao sair do quadro-negro e se tornar visível e palpável é capaz de deixar mentes inquietas, em estado de perplexidade, ao ser finalmente entendido o fenômeno e logo instigando-as para compreender mais dessa surpreendente área que está presente a todo momento em nosso dia a dia.

\section{Agradecimentos}

Agradecemos ao Colégio Estadual Dona Iayá pela oportunidade concedida e aos colegas do PIBID. O presente trabalho foi realizado com o apoio do Programa Institucional de Bolsa de Iniciação à Docência - PIBID, da CAPES Coordenação de Aperfeiçoamento de Pessoal de Nível Superior - Brasil.

\section{Referências}

[1] ABBAGNANO, Nicola; VISALBERGHI, Aldo. História da Pedagogia. Tradução de Glicínia Quartin. Lisboa: Livros Horizonte, s/d. v. II. 419 p.

[2] AGUAYO, Alfredo Miguel. Didática da Escola Nova. Tradução de João Baptista Damasco Penna e Antônio d'Ávila. 14. ed. São Paulo: Nacional, 1970. 368 p.

[3] BOGDAN, Robert C.; BIKLEN, Sari Knopp. Tradução de Maria João Alvarez, Sara Bahia dos Santos e Telmo Mourinho Baptista. Investigação qualitativa em educação: uma introdução à teoria e aos métodos. Porto: Porto Editora, 1994. 337

[4] BORDENAVE, Juan Díaz; PEREIRA, Adair Martins. Estratégias de ensinoaprendizagem. 29. ed. Petrópolis: Vozes, 2008. $316 \mathrm{p}$

[5] BRUBACHER, John Seiler. John Dewey. In: CHÂTEAU, Jean. Os grandes pedagogistas. Tradução de Luiz Damasco Penna e João Baptista Damasco Penna. São Paulo: Nacional, 1978. 358 p.

[6] DEWEY, John. Como pensamos: como se relaciona o pensamento reflexivo com o processo educativo - uma reexposição. Tradução de Haydée de Camargo Campos. 3. ed. São Paulo: Nacional, 1959. 292 p. [A primeira edição, em inglês, é de 1910]

[7] EBY, Frederick. História da Educação moderna: teoria, organização e práticas educacionais. Tradução de Maria Angela Vinagre de Almeida, Nelly Aleotti Maia e Malvina Cohen Zaide. 2. ed. Porto Alegre: Globo, 1976. 633 p.
[8] NÉRICI, Imídeo Giuseppe. Metodologia do Ensino Superior. 2. ed. Rio de Janeiro: Fundo de Cultura, 1973. 349 p. 